\title{
ANALISIS MATRIKS BCG (BOSTON CONSULTING GROUP) DALAM STRATEGI MEMPERTAHANKAN PANGSA PASAR PADA SMARTPHONE MEREK SAMSUNG (STUDI KASUS PADA PT. SAMSUNG ELEKTRONIK INDONESIA TAHUN 2019)
}

\author{
ANALYSIS OF THE BCG (BOSTON CONSULTING GROUP) MATRIX IN THE \\ STRATEGY OF DEFENDING MARKET SHARE ON SAMSUNG BRAND \\ SMARTPHONE \\ (CASE STUDY OF PT. SAMSUNG ELEKTRONIK INDONESIA TAHUN 2019)
}

Kiki Maristia, Anur Anisa Fitri, Erika Yulistiara, Kurnia Yuni Setianingrum, Vicky F Sanjaya

Universitas Islam Negeri Raden Intan Lampung

Kikimaristia51830@gmail.com

Abstract: The purpose of this research itself is to determine the market position PT Samsung Elektronik Indonesia in the BCG matrix (Boston Consulting Group) and formulating strategies to maintain market share. This type of research used in this research is to use descriptive methods. While this research data collection technique uses secondary data based on written documents in the form of sales results and market share PT Samsung Elektronik Indonesia. The calculation result of BCG Matrix owned by PT Samsung Elektronik Indonesia shows that the company is in the position of Cash Cows where the position has a medium market growth with high market share. Thus the company can formulate strategies in the form of product development and diversification.

Keywords: BCG (Boston Consulting Group Matrix), Implementation of Strategies, Market Share Defense

\section{LATAR BELAKANG}

Seiring dengan perkembangan zaman saat ini kebutuhan manusia akan smartphone semakin meningkat, hal ini tercermin pada tingkat penjualan smartphone dari berbagai merek yang terus mengalami peningkatan setiap tahunnya. Pengguna smartphone pada zaman dahulu hanya sebatas digunakan oleh kalangan-kalangan elit, namun saat ini penggunanya sudah merambah ke berbagai kalangan masyarakat mulai dari anak-anak hingga orangtua. Masyarakat biasa pun sudah banyak yang menggunakannya. Hal ini tentunya karena kegunaan smartphone yang sangat multi fungsi dan juga digunakan sebagai sarana untuk mendapatkan informasi. Produk smartphone dapat dinilai potensial oleh konsumen apabila memiliki keunggulan dan kualitas yang sesuai dengan harapan konsumen. Meskipun pada dasarnya 
setiap produk memiliki keunggulan yang kompetitif, namun tidak jarang juga banyak produk yang kalah saing di pasaran karena tidak mampu bersaing dengan para pesaing. Perusahaan dituntut memiliki kemampuan dan juga strategi agar tidak kalah dalam bersaing di pasar. Keunggulan kompetitif sangat diperlukan perusahaan yang ingin sukses di pasaran.

Perusahaan smartphone saat ini tengah gencar memasarkan produknya, mulai dari merek Samsung, Huawei, Iphone, hingga yang terbaru yaitu Realme yang merupakan besutan dari Oppo. Perusahaan-perusahaan tersebut bersaing dengan mengeluarkan produk terbaru yang dibalut dengan fasilitas canggih sehingga dapat menarik konsumen. Diperlukan kegiatan pemasaran yang baik sebagai faktor pendukung utama. Pemasaran sendiri merupakan bagian dari manajeman perusahaan dan juga salah satu faktor yang sangat penting, karena pemasaran akan mempengaruhi kelancaran maupun keberhasilan perusahaan dalam mencapai tujuannya. Oleh karena itu, kelancaran suatu perusahaan sangat tergantung pada manajemen dalam menyusun strategi pemasaran yang akan datang, baik dalam jangka pendek maupun jangka panjang. Strategi pemasaran berkaitan dengan bauran pemasaran yang meliputi $4 \mathrm{P}$ yaitu Product, price, place, promotion, dan tidak lepas juga dari penyusunan strategi STP (segmentation, Targeting, Positioning). Dimana strategi tersebut saling berkaitan satu sama lain dan akan mempengaruhi strategi pemasaran. Dalam menjalankan strategi pemasaran, perusahaan juga sangat perlu untuk mengetahui posisi pangsa pasar dari produknya. Analisis yang perlu dilakukan adalah menggunakan Matrik BCG yang dilakukan untuk mengetahui posisi perusahaan dari segi tingkat pertumbuhan pasar dan pangsa pasar dibandingkan dengan pesaing potesialnya. Menurut Firda, Sri dan dadang (2019) Salah satu cara untuk mengetahui posisi perusahaan dan mempersiapkan strategi yang tepat pada perusahaan tersebut ialah dengan menggunakan Matriks Boston Consulting Group (BCG).

Matriks BCG (Boston Consulting Group) merupakan sebuah matriks yang dibuat oleh Bruce D. Henderson pada tahun 1970 untuk membantu perusahaan dalam menganalisis unit bisnis atau lini bisnis perusahaan. Menurut Yanuar dalam Husein Umar (1999:200) Matrik BCG adalah matrik dan internalexternal (IE) matrik yang dibentuk secara khusus dalam rangka meningkatkan usahausaha perusahaan yang memiliki multidivisi dengan merumuskan strategi yang paling cocok. Matriks BCG merupakan matriks yang secara grafis menggambarkan perbedaan antardivisi dalam posisi pangsa pasar 
relatif dan tingkat pertumbuhan industri. Matriks BCG memungkinkan organisasi atau perusahaan untuk mengelola bisnisnya dengan menguji posisi pangsa pasar relatif dan tingkat pertumbuhan industri relatif dibandingkan dengan divisi lain (pesaing) dalam perusahaan industri yang sama. (David, 2016:177). Matriks BCG terdiri dari 4 posisi yaitu Stars, Cash Cows, Question marks, Dogs. Yusuf dan sony (2014) melakukan penelitian dalam kaitannya dengan matriks BCG, penelitian dilakukan terhadap produk yang menempati kuadran (posisi) yang berbeda-beda, sehingga strategi yang harus dilakukan pun terklasifikasi sesuai dengan kuadran yang di tempati. Dalam penelitian tersebut matriks BCG memiliki pengaruh positif terhadap pertumbuhan penjualan dan juga pangsa pasar perusahaan.

Obyek penelitian dari penulisan ini sendiri adalah PT. Samsung Elektronik Indonesia, yang merupakan perusahaan manufaktur elektronik asal korea selatan yang telah berdiri selama puluhan tahun di Indonesia. Samsung saat ini tengah merajai persaingan pasar telekomunikasi di Indonesia bahkan hingga ke berbagai Negara. Seiring dengan perkembangan kondisi ekonomi serta tumbuhnya pemasaran smartphone, PT. Samsung Elektronik Indonesia berhasil memantapkan posisinya yang pertama dan tak terkalahkan dengan catatan penjualan tahun 2019 mencapai 76. 600.000 unit. Posisi ini juga turut mendorong Samsung menguasai pangsa pasar mencapai $21,3 \%$ dari total keseluruhan penjualan smartphone di pasar domestik.

Untuk mempertahankan atau bahkan meningkatkan penguasaan pasar tersebut Samsung perlu mengetahui posisi perusahaannya dalam industri smartphone, karena salah satu tujuan suatu perusahaan adalah untuk memaksimumkan nilai perusahaan dan mencapai hasil kerja yang maksimal bagi perusahaan. Maka pihak manajemen perusahaan Samsung tersebut perlu mengetahui faktor-faktor yang mempengaruhi pangsa pasar relatif dan pertumbuhan pasar dengan mengambil perbandingan kepada pesaingnya dan untuk kemudian dapat menerapkan strategi mempertahankan posisi pangsa pasar dari perusahaan Samsung tersebut. Maka pihak manajemen dapat menerapkan konsep strategi penjualan menggunakan matriks BCG. Setelah mengetahui posisi perusahaan dalam matriks BCG, maka Samsung akan mengetahui posisi perusahaanya sedang berada dimana, selanjutnya Samsung dapat menciptakan sebuah strategi sesuai dengan kuadran yang dicapainya dalam Matriks BCG. Dari latar belakang tersebut maka judul penelitian yang diangkat Adalah Analisis Matriks BCG (Boston Consulting Grup) dalam 
mempertahankan pangsa pasar (Studi Kasus Pada PT. Samsung Elektronik Indonesia tahun 2019).

\section{PERUMUSAN MASALAH}

Berdasarkan fenomena yang telah dikemukakan maka rumusan masalah dalam penelitian ini adalah sebagai berikut:

1. Bagaimana posisi PT. Samsung Elektronik Indonesia dalam kuadran matriks BCG?

2. Bagaimana strategi PT. Samsung Elektronik Indonesia dalam mempertahankan pangsa pasar sebagai posisi tertinggi?

\section{TUJUAN PENELITIAN}

Tujuan penelitian yang ingin dicapai yaitu untuk mengetahui posisi perusahaan dalam kuadran matriks $\mathrm{BCG}$, sebagai upaya untuk merumuskan strategi dalam mempertahankan pangsa pasar bagi PT. Samsung Elektronik Indonesia.

TINJAUAN PUSTAKA Matriks BCG (Boston Consulting Group)

\section{a. Pengertian Matriks BCG}

Matriks BCG merupakan matriks yang secara grafis menggambarkan perbedaan antardivisi dalam posisi pangsa pasar relatif dan tingkat pertumbuhan industri. (David, 2016:177). Matriks BCG juga dapat diartikan sebagai metode dalam mengevaluasi bisnis relatif terhadap tingkat pertumbuhan dari pasar bisnis dan pangsa organisasi dalam pasar. (Grifin, 2016:245). Menurut Yanuar dalam Husein Umar (1999:200) Matrik BCG adalah matrik dan internalexternal (IE) matrik yang dibentuk secara khusus dalam rangka meningkatkan usahausaha perusahaan yang memiliki multidivisi dengan merumuskan strategi yang paling cocok. Suwarsono (2008:25) mengemukakan Matriks BCG mulanya di desain untuk melihat posisi portofolio unit bisnis yang diperlukan oleh manajemen pada tingkat korporat. Posisi pasar yang tergambar disusun sesuai dengan kakteristik pasar yang melekat pada masing-masing unit usaha strategik. Dalam perkembangannya kemudian alat analisis ini digunakan untuk melihat bukan saja portofolio bisnis, tetapi juga portofolio produk.

Para manajer yang menggunakan matriks BCG memplot setiap bisnis perusahaan beserta tingkat pertumbuhan pasar dan posisi kompotitif relatif. Tingkat pertumbuhan pasar (market growth rate) merupakan proyeksi tingkat pertumbuhan penjualan untuk pasar yang dilayani untuk suatu bisnis. Biasa, indikator ini diukur 
sebagai persentase kenaikan dalam penjualan atau volume unit sela dua tahun terakhir. Tingkat pertumbuhan ini berfungsi sebagai indikator daya tarikrelatif dari pasar yang dilayani oleh setiap bisnis dalam portofolio bisnis perusahaan tersebut. Posisi kompetitif relatif (relative competitive position) biasanya dinyatakan sebagai pangsa pasar dari suatu bisnis dibagi dengan pangsa pasardari pesaing terbesarnya. Dengan demikian, kompetitif relatif menjadi dasar untuk membandingkan kekuatan dari relatif dari bisnis-bisnis yang ada di portofolio perusaan dalam hal posisi dari masing-masing bisnis tersebut di pasarnya. (Pearce II, 2008:346). Matriks Boston Cosulting Group memiliki tingkatan dalam setiap kuadrannya, yang memiliki 4 posisi, yaitu : Stars, Cash Cows, Question Marks, Dogs. Metode analisis matriks BCG membantu perusahaan untuk mengetahui posisi dirinya di dalam empat kategori, yakni kategori Anjing (Dogs), Tanda Tanya (Question Marks), Bintang (Stars), dan Sapi perah (Cash Cows), yang penentuannya didasarkan pada kombinasi dari pertumbuhan pasar dan pangsa pasar relatif terhadap pesaing terbesar. Matriks ini juga dapat digunakan untuk menempatkan produk strategis yang dapat menghasilkan keuntungan bagi perusahaan.

1. Bintang (stars)

Melambangkan bisnis-bisnis yang berada di dalam pasar yang tumbuh pesat dengan pangsa pasar yang besar. Bisnis-bisnis ini mencerminkan peluang jangka panjang terbaik (pertumbuhan \& profaprofitabilitas) dalam portofolio. Bisnis bisnis tersebut membutuhkan investasi yang stubstansi untuk mempertahahankan (dan memperluas) posisinya yang dominan dalam suatu pasar yang bertumbuh. Kebutuhan akan investasi ini sering kali melebihi dana yang dapat dihasikan oleh bisnis-bisnis tersebut secra internal. Oleh karna itu, bisnis-bisnis ini sering kali merupakan pengguna utama sumber daya korporat dalam jangka pendek.

\section{Sapi Perah (Cash Cows)}

Adalah bisnis yang memiliki pangsa pasar besar dalam pasar atau industri dengan pertumbuhan rendah. Karena posisi kompetitifnya yang kuat dan kebutuhan akan reinvestasi yang minimum, bisnis-bisnis seringkali menghasilkan kas melebihi kebutuhannya. Dengan 
demikian, bisnis-bisnis ini secara selektif "diperah" sebagai salah satu sumber daya korporat untuk digunakan di tempat lain (ke bintang dan tanda Tanya).

3. Tanda Tanya (Question Marks)

Merupakan bisnis-bisnis yang tingkat pertumbuhannya tinggi sehingga memiliki daya tarik yang besar namun pangsa pasarnya rendah sehingga membuat potensi labanya menjadi tidak pasti. Bisnis ini disebut tanda tanya karena organisasi harus menentukan apakah akan memperkuat dengan mengejar strategi intensif (penetrasi pasar, pengembangan pasar, atau pengembangan produk) atau menjualnya.

\section{Anjing (Dogs)}

Bisnis-bisnis dengan pangsa dan pertumbuhan pasar yang rendah. (Pearce II, 2008:346). Karena posisi eksternal dan internal mereka lemah, bisnis dalam posisi ini sering kali dilikuidasi, dikurangi, atau dilepaskan.

(David,

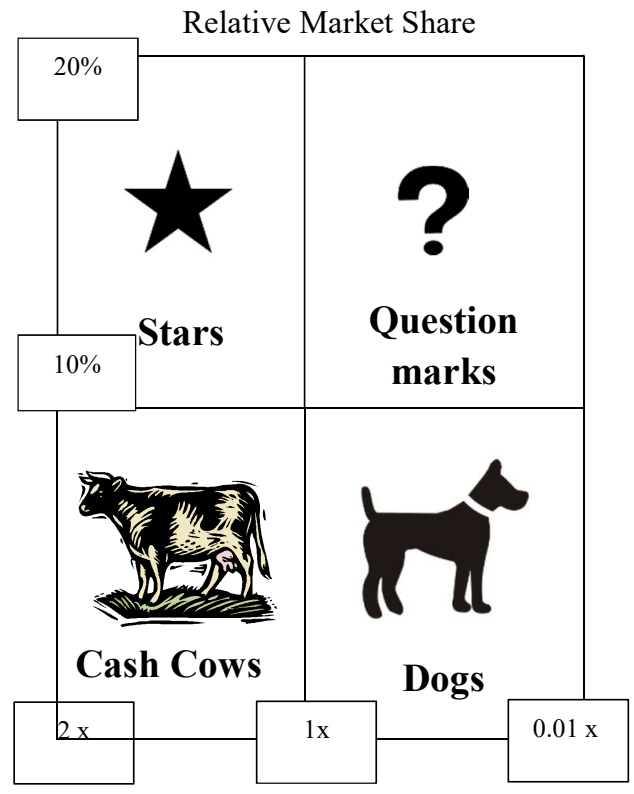

Gambar 1 Matriks BCG

Posisi pangsa pasar relatif diberikan pada sumbu $\mathrm{x}$ dari matriks BCG. Titik tengah dari sumbu $\mathrm{x}$ biasanya dibuat 0,50 atau sama dengan divisi yang memiliki separuh pangsa pasar dari perusahaan pemimpin dalam industri. Sumbu y menggambarkan tingkat pertumbuhan industri dalam penjualan yang diukur dalam bentuk persentase. Persentase tingkat pertumbuhan pada sumbu y dapat berkisar antara -20 hingga +20 persen, dengan 0,0 sebagai titik tengah. Angka kisaran ini pada sumbu $\mathrm{x}$ dan $\mathrm{y}$ seringkali digunakan, tetapi angka lainnya dapat dibuat bila dianggap sesuai untuk organisasi tertentu. (David, 2016:179). Dari keempat kuadran tersebut perusaahaan dapat menentukan 
strategi terhadap masing-masing kuadran, dan akan lebih jelas lagi dalam menentukan strategi perusahaan bertahan di pasar dan juga dalam menghadapi pesaing. Bagi perusahaan yang sudah berdiri lama dalam suatu industri tertentu, dan dalam industri tersebut terdapat beberapa perusahaan (pesaing) yang masih dapat di tolerir, dengan perkembangan pasar yang cukup baik maka produk dari perusahaan tersebut masuk dalam kuadran question marks atau juga bisa masuk dalam kuadran stars. Karena perusahaan yang berada pada pasar yang masih stabil mengalami perkembangan dan jumlah pemain yang berada dalam industri tersebut masih sesuai dengan rasio pasar yang ada, maka perusahaan tersebut masuk dalam kondisi question marks. Poin utama dari konsep matriks BCG adalah memperhatikan kondisi pesaing dan potensi pasar, karena kedua kombinasi ini merupakan faktorfaktor yang sangat penting dan baik dalam praktek maupun teori untuk memahami konsep matriks BCG. Jika perusahaan memiliki pangsa pasar yang baik maka perusahaan masuk dalam kondisi cash cows, tetapi jika sebaliknya maka perusahaan berada dalam kondisi kritis dogs. Setiap tingkatan dan kategori dalam matriks BCG membutuhkan pemahaman dan perlakuan yang berbeda-beda (khusus). Tidak dapat begitu saja meningkatkan investasi pada saat perusahaan berada dalam kuadran stars, karena bukan tidak mungkin pertumbuhan pasar yang stabil akan mengundang banyak pesaing baru ke pasar yang ada. Atau ketika perusahaan berada dalam kuadran $\operatorname{dogs}$, biasanya perusahaan akan langsung menutup semua produksi yang ada pada produk yang bersangkutan tetapi hal ini bisa diatasi dengan melakukan inovasi atau perubahan target pasar dengan memanfaatkan inovasi pasar yang belum tergarap. Demikian pula ketika perusahaan berada di posisi cash cows maupun question marks, harus memperhatikan banyak faktor yang saling berkaitan dan masing-masing dapat berubah sesuai dengan peristiwa yang ada dan sangat sulit untuk diprakirakan.

\section{b. Tujuan Matriks BCG}

Menurut Rangkuti (2006) tujuan matriks BCG adalah:

a. Mengembangkan strategi pangsa pasar untuk portofolio produk berdasarkan karakteristik cash flow-nya.

b. Mengembangkan portofolio produk perusahaan sehingga jelas kekuatan dan kelemahannya. 
c. Memutuskan apakah perlu meneruskan investasi untuk produk yang tidak menguntungkan.

d. Mengalokasikan anggaran pemasaran produk guna memaksimalkan cash flow jangka panjang.

e. Mengukur kinerja manajemen berdasarkan kinerja produk di pasaran.

\section{c. Keuntungan Matriks BCG}

Keuntungan terbesar dari matriks BCG adalah ia menarik perhatian ke aliran kas, karakteristik investasi, dan kebutuhan berbagai divisi perusahaan. Dalam beberapa organisasi, tidak ada perputaran siklis yang nyata. Divisi-divisi dari perusahaan berevolusi dari waktu ke waktu: anjing menjadi tanda Tanya, tanda Tanya menjadi bintang, bintang menjadi sapi perah, dan sapi perah menjadi anjing dan berputar secara berkelanjutan. Namun yang jarang terjadi adalah bintang berubah menjadi tanda Tanya, tanda Tanya menjadi anjing, anjing menjadi sapi perah dan aliran kas menjadi bintang. Selama beberapa waktu, organisasi sebaiknya berusaha untuk mendapatkan portofolio divisi yang merupakan bintang. (David, 2016:180). d. Mengumpulkan Data Statistik Yang Diperlukan Untuk Analisis

- Data penjualan tahunan tiap produk

- Data penjualan tahunan kompetitor (untuk produk yang sama)

- Tingkat pertumbuhan tahunan tiap produk (dalam bentuk persen)

\section{e. Menghitung Pangsa Pasar Relatif}

Yaitu dengan cara membagi penjualan tahunan produk terhadap total penjualan kompetitor.

- Jika pangsa pasar $=1$, artinya perusahaan ini memiliki pangsa pasar sama dengan kompetitor utama.

- Jika pangsa pasar < 1 , artinya perusahaan ini memiliki pangsa pasar lebih kecil dari kompetitor utama.

- Jika pangsa pasar > 1, artinya perusahaan memiliki pangsa pasar lebih besar dari kompetitor utama.

\section{f. Membuat Plot Pangsa Pasar} Pada Diagram Matriks BCG

1. Masing-masing perusahaan dibuatkan plot sesuai dengan market growth rate (persentase pertumbuhan 
penjualan) dan posisi relatif

dengan pesaing (market share). Market growth rate adalah proyeksi tingkat penjualan untuk pasar yang akan dilayani. Biasanya diukur dengan peningkatan persentase dalam nilai/volume penjualan dua tahun terakhir.

2. Market growth rate merupakan indikator relatif attractiveness dari pangsa pasar dibagi dengan pangsa pasar dari pesaing yang paling dominan.

3. Posisi relative competition merupakan perbandingan dasar dari relative strength dari berbagai bisnis yang berbeda dalam portofolio bisnis, dalam kaitanya dengan kekuatan masingmasing posisi di business's respective market.

4. Apabila kita ingin mengetahui posisi relatif antara masing-masing SBU (strategic business unit) maka SBU tersebut dapat dibuatkan plotnya dalam matriks BCG. Tetapi masing-masing SBU tersebut harus dihitung besarannya terlebih dahulu dalam bentuk pie diagram. Masing-masing lingkaran mewakili satu bisnis unit. Luas lingkaran mewakili provinsi tingkat pendapatan perusahaan yang dihasilkan masing-masing bisnis unit. Secara keseluruhan, hal ini dapat memberikan gambaran kekuatan masingmasing bisnis unit di dalam menghasilkan pendapatan. (Rangkuti, 2006:37).

\section{g. Strategi Yang Dapat Diterapkan Perusahaan Saat Berada Pada Posisi Kuadran}

Strategi adalah rencana lengkap untuk mencapai tujuan organisasi. (Grifin, 2016:245). Menurut Adi Yusup, Hendang dan dwi dalam Porter (2011) Strategi menurutnya adalah penciptaan posisi unik dan berharga yang didapatkan dengan melakukan serangkaian aktivitas. Porter juga pernah menuliskan bahwa esensi dari strategi adalah memilih aktivitas yang tidak dilakukan oleh pesaing atau lawan. Sedangkan menurut Firda, Sri dan Dadang dalam Solihin (2012:24) pada awalnya konsep strategi (strategy) didefinisikan sebagai berbagai cara untuk mencapai tujuan (ways to achieve ends). Dapat diartikan bahwa strategi ialah suatu tatanan, cara ataupun konsep pada sebuah perusahaan untuk mencapai tujuan dari perusahaan tersebu Menurut Rufaidah (2013) berdasarkan posisi perusahaan bila berada pada kuadran-kuadran tersebut, 
maka alternatif strategi yang dapat diterapkan perusahaan bila berada pada posisi sebagai berikut.

Tabel 1

Strategi dalam Matriks BCG

\begin{tabular}{|l|l|l|l|}
\hline STARS & \multicolumn{1}{|c|}{$\begin{array}{c}\text { CASH } \\
\text { COWS }\end{array}$} & $\begin{array}{l}\text { QUESTION } \\
\text { MARKS }\end{array}$ & DOGS \\
\hline $\begin{array}{l}\text { Intregras } \\
\text { i ke } \\
\text { belakang }\end{array}$ & $\begin{array}{l}\text { Pengembang } \\
\text { an produk }\end{array}$ & $\begin{array}{l}\text { Penetrasi } \\
\text { pasar }\end{array}$ & $\begin{array}{l}\text { Penciuta } \\
\mathrm{n}\end{array}$ \\
\hline $\begin{array}{l}\text { Integrasi } \\
\text { ke depan }\end{array}$ & Diversifikasi & $\begin{array}{l}\text { Pengembang } \\
\text { an pasar }\end{array}$ & $\begin{array}{l}\text { Divestas } \\
\mathrm{i}\end{array}$ \\
\hline $\begin{array}{l}\text { Integrasi } \\
\text { horizont } \\
\text { al }\end{array}$ & Penciutan & $\begin{array}{l}\text { Pengembang } \\
\text { an produk }\end{array}$ & $\begin{array}{l}\text { Likuidas } \\
\mathrm{i}\end{array}$ \\
\hline & & Divestasi & \\
\hline
\end{tabular}

adapun penjelasan alternatif strategi tersebut dijelaskan sebagai berikut:

1. Stratetegi integrasi:

- Integrasi ke depan: memperoleh kepemilikan atau kendali yang lebih besar atas fungsi perantara atau distributor atau peritel atau bisa juga reseller

- Integrasi ke Belakang: mengupayakan

kepemilikan atau kendali yang lebih besar atas pemasok perusahaan.

- Integrasi horizontal: mengupayakan

kepemilikan atau kendali yang lebih besar atas pesaing dilakukan melalui akuisisi, merger dan pengambilalihan (takeover) di antara pesaing.
- Integrasi vertikal: mengupayakan

kepemilikan atau kendali yang lebih besar atas distributor, pemasok atau pesaing.

\section{Strategi intensif:}

- Penetrasi pasar: mencari pangsa pasar yang lebih besar untuk produk atau jasa saat ini di pasar yang ada sekarang melalui upaya-upaya pemasaran yang lebih baik

- Pengembangan pasar: memperkenalkan produk atau jasa saat ini ke wilayah geografis baru.

- Pengembangan produk: mengupayakan peningkatan penjualan melalui perbaikan produk atau jasa saat ini atau pengembangan produk atau jasa baru.

\section{Strategi diversifikasi:}

- Diversifikasi terkait: menambah produk atau jasa yang baru namun masih berkaitan.

- Diversifikasi tidak terkait: menambah produk atau jasa yang baru namun tidak berkaitan.

\section{Strategi pertahanan:}

- Penciutan:

pengelompokan ulang melalui pengurangan biaya dan aset untuk 
membalik penjualan dan laba yang menurun.

- Divestasi: penjualan suatu divisi atau bagian dari sebuah organisasi yang bertujuan untuk mendapatkan modal untuk akuisisi atau investasi strategi lainnya.

- Likuidasi: penjualan seluruh aset perusahaan, secara terpisah-pisah untuk kekayaan berwujudnya.

\section{METODOLOGI PENELITIAN}

\section{a. Jenis Penelitian}

Jenis penelitian yang digunakan dalam penelitian ini adalah dengan menggunakan metode deskriptif. Menurut Sugiyono (2010) penelitian deskriptif adalah metode yang digunakan untuk menganalisis data yang telah terkumpul sebagaimana adanya tanpa bermaksud membuat kesimpulan yang berlaku untuk umum atau generalisasi.

\section{b. Teknik Pengumpulan Data}

Penelitian ini menggunakan data sekunder berdasarkan dokumen tertulis berupa hasil penjualan dan pangsa pasar PT Samsung Elektronik Indonesia berasal dari situs global smartphone shipment and market share.

\section{c. Bagan Alir Tahapan Penelitian}

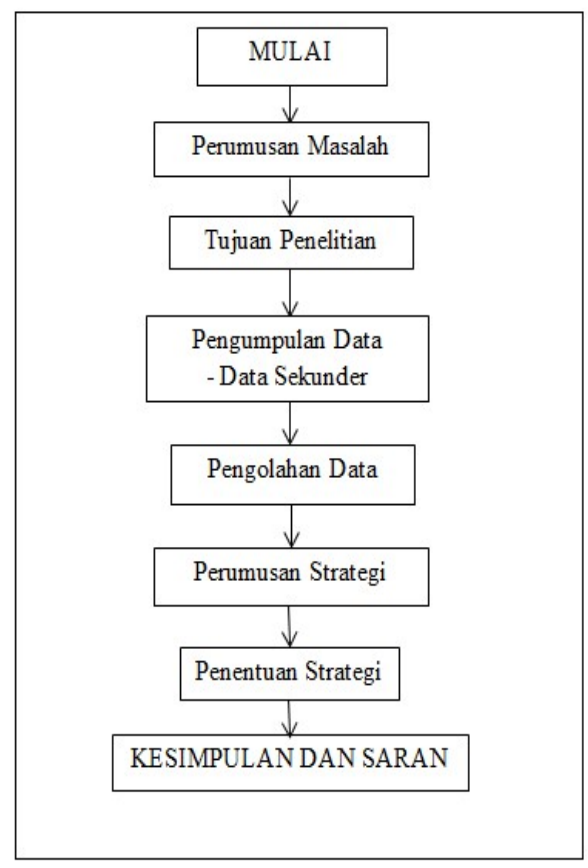

Gambar 2 Bagan Alir Tahapan Penelitian

\section{HASIL DAN PEMBAHASAN}

\section{Matriks BCG PT Samsung Elektronik Indonesia}

Matrik BCG ini akan digunakan untuk mengetahui posisi PT Samsung Elektronik Indonesia dari pertumbuhan penjualan dan pangsa pasar perusahaan tersebut. Jika sudah diketahui posisinya, maka akan dapat ditentukan strategi yang dapat digunakan untuk mempertahankan pangsa pasar oleh perusahaan. Berikut ini adalah daftar laporan penjualan PT Samsung Elektronik Indonesia tahun 2019 yang dapat dilihat pada gambar berikut ini: 


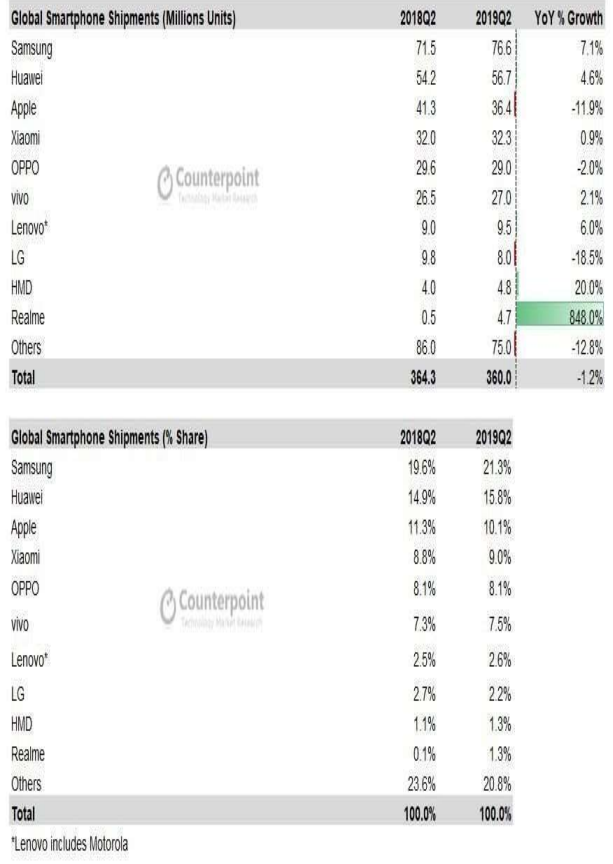

Sumber: Global Smartphone Shipment and Market Share

\section{Gambar 3 Penjualan Smartphone Samsung}

Melalui data tersebut kita dapat memperoleh hasil pertumbuhan pasar penjualan smartphone PT Samsung Elektronik Indonesia dengan rumus :

$\frac{\sum \text { Penjualan } 2019-\sum \text { Penjualan } 2018 \times 100 \%}{\sum \text { Penjualan } 2018}$

Dengan hasil sebagai berikut:

Pertumbuhan penjualan $=$

$\underline{76.600 .000-71.500 .000} \times 100 \%$

71.500 .000

$$
=7,13 \%
$$

Berdasarkan perhitungan dengan menggunakan matriks BCG di atas, maka dapat diketahui tingkat pertumbuhan pasar penjualan smartphone PT Samsung Elektronik Indonesia sebesar 7,13 \% yang berarti bahwa PT Samsung Elektronik Indonesia memiliki pertumbuhan pasar yang sedang.

Kemudian langkah selanjutnya adalah mencari pangsa pasar smartphone Samsung dengan menggunakan data penjualan tahun terakhir dibandingkan terhadap pesaing Samsung yaitu penjualan Huawei pada tahun terakhir. Huawei diperhitungkan sebagai pesaing potensial karena dari data diatas pada tahun 2018 dan 2019 Huawei menjadi produsen smartphone dengan penjualan tertinggi kedua dibawah PT Samsung Elektronik Indonesia dan pada tahun 2019 menguasai pangsa pasar smartphone sebesar 15,8\%. Pangsa pasar relatif sendiri merupakan bagian penjualan industri total sebuah perusahaan disebuah pasar tertentu. Data yang digunakan adalah data jumlah penjualan smartphone Samsung tahun 2018 dan tahun 2019 dan data volume penjualan kompetitor yaitu jumlah penjualan smartphone Huawei tahun 2018 dan tahun 2019 digunakan sebagai pembagi dari total volume jumlah penjualan smartphone Samsung 2018 dan tahun 2019. Berikut perhitungan matriks BCG untuk mengetahui pangsa pasar relatif (relative market share) jumlah penjualan smartphone PT Samsung Elektronik Indonesia tahun 2018 dan tahun 2019: 
Pangsa Pasar $2018\left(X_{1}\right)$

$X_{1}=\frac{\sum \text { Penjualan Samsung } 2018}{\sum \text { Penjualan Huawei } 2018}$

Pangsa pasar 2018( $\left.\mathrm{X}_{1}\right)$

$X_{1}=\frac{71 \cdot 500 \cdot 000}{54 \cdot 200 \cdot 000}=1,31 \mathrm{kali}$

Pangsa Pasar $2019\left(X_{2}\right)$

$X_{2}=\frac{\sum \text { Penjualan Samsung } 2019}{\sum \text { Penjualan Huawei } 2019}$

Pangsa pasar $2019\left(\mathrm{X}_{2}\right)$

$X_{2}=\frac{76.600 .000}{56.700 .000}=1,35 \mathrm{kali}$

Berdasarkan perhitungan matriks BCG untuk mengetahui pangsa pasar relatif (relative market share) maka telah diketahui bahwa pangsa pasar relatif Samsung tahun 2018 sebesar 1,31 kali > 1 dan pada tahun 2019 sebesar 1,35 kali > 1 yang artinya menunjukkan bahwa PT Samsung Elektronik Indonesia memiliki pangsa pasar lebih besar dibandingkan dengan Huawei karena nilai pangsa pasar relatifnya lebih besar dari satu. PT Samsung Elektronik Indonesia pada tahun 2018 sebesar 1,31 menjadi 1,35 pada tahun 2019, dengan kata lain mengalami kenaikan sebesar 0,04 .

Selanjutnya setelah mengetahui perhitungan tingkat pertumbuhan pasar pada PT Samsung
Elektronik Indonesia yang telah diperoleh hasil sebesar 7,13\%, hal ini menandakan bahwa tingkat pertumbuhan pasar PT Samsung Elektronik Indonesia masuk dalam kategori sedang. Sedangkan dari perhitungan pangsa pasar relatif pada tahun 2018 didapat hasil sebesar 1,31 kali dan pada tahun 2019 didapat hasil sebesar 1,35 kali dan berikut ini adalah Matrik BCG PT Samsung Elektronik Indonesia.

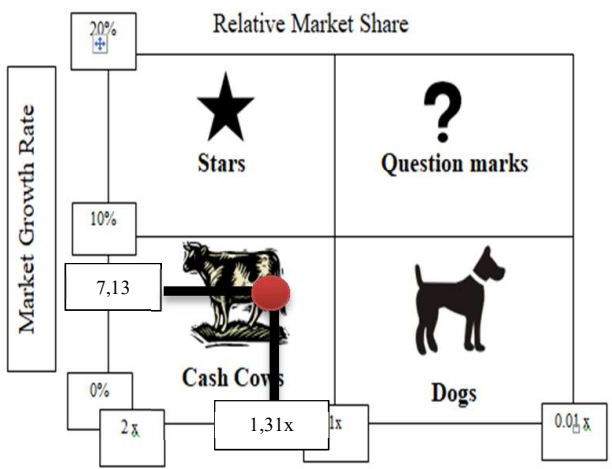

Gambar 4 matriks BCG PT Samsung Elektronik Indonesia 2018

Dan berikut ini adalah matriks BCG PT Samsung Elektronik Indonesia untuk tahun 2019:

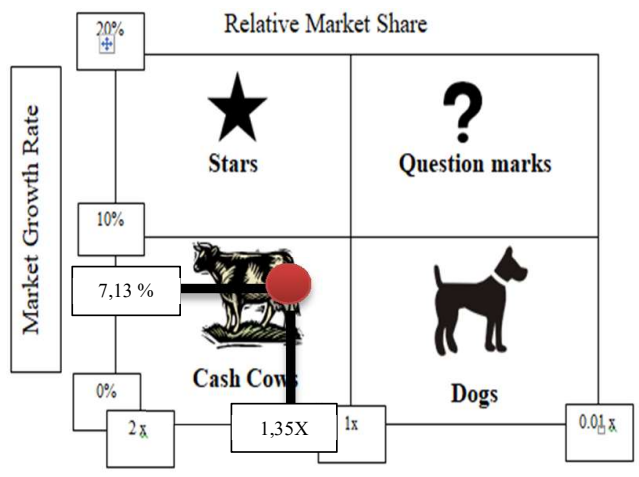


Gambar 5 matriks BCG PT Samsung Elektronik Indonesia 2019

Berdasarkan dari perhitungan tersebut dapat diketahui bahwa PT Samsung Elektronik Indonesia tahun 2019 berada pada posisi Cash Cows (sapi perah) dengan pertumbuhan penjualan yang masuk tingkat sedang dan pangsa pasar relatif (market share relative) yang tinggi karena nilainya lebih dari $\operatorname{satu}(>1)$.

\section{STRATEGI PT. SAMSUNG DALAM MEMPERTAHANKAN PANGSA PASAR}

Dari perhitungan yang telah dilakukan menggunakan matriks BCG, PT Samsung Elektronik tahun 2019 memiliki tingkat pertumbuhan penjualan yang sedang dengan tingkat pangsa pasar yang relatif tinggi bila dibandingkan dengan perusahaan kompetitor. Sehingga hal ini menentukan bahwa PT Samsung Elektronik Indonesia berada pada posisi Cash Cows (sapi perah). Asumsi posisi Cash Cows (sapi perah) apabila perusahaan berada dalam pertumbuhan penjualan antara $0-10 \%$ dan pangsa pasar $1-10 x$.

Arti posisi perusahaan berada pada tingkatan Cash Cows adalah perusahaan menghasilkas kas yang melebihi kebutuhannya dan sering "diperah". Pada posisi ini (sesuai dengan strategi yang telah dijelaskan sebelumnya) sebaiknya perusahaan harus mampu mengelola dana untuk mempertahankan posisi kuat dan posisi tertingginya selama mungkin dari para pesaing. Pengembangan produk dengan menggunakan strategi intensif juga dapat diterapkan dengan cara mengupayakan peningkatan penjualan melalui perbaikan produk atau jasa saat ini atau pengembangan produk atau jasa baru. Selain itu strategi diversifikasi bisa menjadi strategi yang menarik bagi perusahaan saat berada pada posisi ini. Tetapi apabila posisi perusahaan melemah, maka strategi yang dapat dilakukan adalah menggunakan strategi penciutan atau divestasi.

Alternatif strategi lainnya yang dapat diterapkan adalah ketika profit dan aliran kas perusahaan dalam posisi cukup tinggi maka perusahaan harus berhati-hati dalam melakukan investasi. Usahakan lebih teliti dalam memilih investasi untuk menjaga tingkat profit yang tinggi. Selain itu perusahaan sebaiknya memikirkan bagaimana cara memutar aset yang dimiliki sehingga menghasilkan keuntungan yang lebih besar lagi. Strategi-strategi tersebut dapat diterapkan oleh PT Samsung Elektronik Indonesia guna untuk mempertahankan pangsa pasar perusahaanya yang sudah berada pada posisi paling tinggi. Setidaknya meskipun dalam kurun waktu dua tahun terakhir pangsa pasar PT Samsung Elektronik Indonesia sudah berada pada posisi paling atas, namun Samsung harus tetap waspada oleh produk pesaingnya, terlebih 
oleh Huawei yang merupakan pesaing potensialnya. Strategi pangsa pasar yang telah diterapkan Samsung pun harus tetap dijalankan mengingat bahwa Samsung telah berada pada posisi pangsa pasar yang tinggi dan kemudian bisa dilakukan dengan menciptakan strategi baru untuk meningkatan pertumbuhan pasarnya. Dengan begitu strategi ini dapat membantu PT Samsung Elektronik Indonesia dalam mempertahankan pangsa pasarnya agar tidak tergeser oleh pesaingnya, dan strategi baru tersebut dapat di terapkan untuk membantu pertumbuhan PT Samsung Elektronik Indonesia di tahun berikutnya.

\section{KESIMPULAN}

1. Matriks BCG pada PT Samsung Elektronik Indonesia ini digunakan untuk mengetahui posisi perusahaan Samsung pada tahun 2019 di antara perusahaan pesaing dengan melihat tingkat pertumbuhan dan pangsa pasarnya dengan cara diuji atau diperhitungkan.

2. Dari hasil perhitungan Matriks BCG tersebut, PT Samsung Elektronik Indonesia pada tahun 2019 memiliki tingkat pertumbuhan penjualan sebesar $7,13 \%$ dan pangsa pasar relatif sebanyak 1,31x di tahun 2018 dan sebanyak $1,35 \mathrm{x}$ di tahun 2019. Hal ini menunjukan bahwa Samsung berada pada pertumbuhan pasar yang sedang dan pangsa pasar relative yang tinggi karena nilainya $>1$.

3. Matriks BCG PT Samsung Elektronik Indonesia berada pada posisi Cash Cow (sapi perah). Yang mengindikasikan PT Samsung Elektronik Indonesia memiliki kas yang melebihi kebutuhannya.

4. Strategi yang dapat diterapkan Samsung untuk tetap bertahan dalam posisi pangsa pasar tertinggi sesuai dengan kuadrannya yakni menggunakan strategi Pengembangan produk, strategi diversifikasi. Kemudian Samsung juga harus berhati-hati ketika akan berinvestasi.

\section{SARAN}

Berdasarkan simpulan di atas, maka penulis memberikan saran sebagai berikut:

1. Hasil dari Matriks BCG PT Samsung Elektronik Indonesia berada pada posisi Cash Cow (sapi perah). Yang mengindikasikan PT Samsung Elektronik Indonesia memiliki kas yang melebihi kebutuhannya. Artinya perusahaan harus hatihati dalam melakukan investasinya agar aliran kas yang masuk tetap terkontrol dan tidak turun.

2. Perusahaan juga diharapkan mampu mempertahankan posisi 
dan dominasi pasar agar tidak tergeser oleh pesaing-pesaingnya.

\section{DAFTAR PUSTAKA}

Barusman, M. Yusuf dan Gunardi, Sony. 2014. Analisis Portofolio Produk pada PT. Asuransi Umum Bumi Putera Muda 1967 cabang Lampung Menggunakan Matrik BOSTON CONSULTING GROUP (BCG). Jurnal Manajemen dan Bisnis Vol. 4 No. 2 April 2014. ISSN : 20870701.

Mulyana, Tatang., Firdaus Rizki. 2017. Analisis Strategi Pemasaran PT. Vivo Communicaton Indonesia Area Garut Dengan Metode Swot dan Matriks BCG. Jurnal Wacana Ekonomi Vol. 17; No. 01; Tahun 2017. ISSN : 1412-5897.

Padil, Adi Yusuf., Rukmi, Hendang Setyo., Kurniawan Dwi. 2015. Usulan Strategi Perusahaan CV Kurnia Jaya Menggunakan Matriks Perumusan Strategi. Jurnal Online Institut Teknologi Nasional No.02, Vol.03 April 2015. ISSN: 23385081.

Prasetyo, Yogi Wahyu., Yulianto, Edy., $\quad$ Sunarti. 2016. Perumusan Strategi Bisnis Perusahaan Menggunakan
Matriks Boston Consilting Group (BCG) dan Matriks TOWS-K. jurnal Administrasi Bisnis (JAB) Vol. 40 No. 1 November 2016

Puteri, Firda Shafira., Nuringwahyu, Sri dan Krisdianto Dadang. 2019. Matriks Boston Consulting Group (BCG) Sebagai Dasar Perencanaan Strategi Perusahaan. JIAGABI Vol. 8, No. 3, 1 Agustus 2019. ISSN $2302-$ 7150.

Putra, Yanuar Surya. 2013. Analisis Matriks Boston Consulting Grup ( BCG ) Pada Sepeda Motor Merek Honda. Among makarti, Vol.7 No.13, Juli 2014.

David, Fred R. 2016. Manajemen Strategik Suatu Pendekatan Keunggulan Bersaing. Jakarta : Penerbit Salemba Empat

Grifin. 2016. Manajemen. Edisi 7. Jilid 1. Jakarta : Penerbit Erlangga

Muhammad, Suwarsono. 2008. Matriks dan Skenario dalam Strategi. Yogyakarta : Unit Penerbit dan Percetakan Sekolah Tinggi Ilmu Mnajemen YKPN.

Pearce, John A. Robinson, Richard B. 2008. Manajemen Strategis Formulasi, Implementasi, dan 
Pengendalian. Jakarta :

Salemba Empat

Rangkuti, Freddy. 2006. Analisis

SWOT Membedah Kasus

Bisnis. Jakarta : Penerbit

Gramedia Pustaka Utama

Rufaidah, Popy. 2013. Manajemen

Strategik Analisis,

Formulasi, Implementasi \&

Evaluasi. Bandung :

Penerbit Humaniora

Sugiyono. 2010. Metode Penelitian

Pendidikan Pendekatan

Kuantitatif, kualitatif, dan

R\&D. Bandung : Penerbit

Alfabeta

https://www.counterpointresearch.co

$\mathrm{m}$ /combined-global-market-

share-huawei-oppo-vivo-

xiaomi-realme-reaches-

highest-ever-level-q2-2019/

(diakses pada 9 april 2020,

pukul 22.14 WIB) 
